\title{
RISK MANAGEMENT IN CONSTRUCTION PROJECTS USING BUILDING INFORMATION MODELLING
}

\author{
Dimitra Papachatzi and Yiannis Xenidis \\ Aristotle University of Thessaloniki, Thessaloniki, Greece
}

\begin{abstract}
Risks reduction in construction projects is feasible through Building Information Modelling (BIM) according to the respective literature; however, so far, BIM-based risk management (RM) has not been addressed in a systematic way. This paper attempts to formalize BIM-based RM by suggesting and demonstrating the performance of a three-stage methodology. The methodology is applied on two risk scenarios in a building project through four commercial software applications that perform in combination, a full risks analysis regarding time and cost levels for the building project. The advantages and disadvantages of the proposed methodology and risk management in construction projects using BIM are presented.
\end{abstract}

\section{Introduction}

Building Information Modelling (BIM) methodology and technology is a way to digitalize planning, design and operation of buildings and infrastructures (EU BIM Task Group, 2017). The majority of large construction enterprises, worldwide, use BIM software for their projects (Lam et al., 2017), while adoption of BIM is increasing year after year, as the AECOO (Architecture, Engineering, Construction, Owner and Operator) industry recognizes the advantages and potential of this technology (Farnsworth et al., 2015).

BIM offers a user-friendly environment for designing and modifying a project's 3D model. Moreover, what constitutes the biggest advantage of this methodology and technology is the data that is contained in the created model (Eastman, 2008) that can describe the geometry and the attributes of the model's elements and can be useful to all phases of the project (Volkov \& Kuzina, 2016). Another critical aspect is that BIM ensures the interoperability of information among different parties involved throughout a project's life cycle (Jupp, 2017).

Based on these features BIM can be a very effective platform for performing risk management (Bråthen \& Moum, 2016; Farnsworth et al., 2015; Kelly \& Ilozor, 2016; Lam et al., 2017; Eadie et al., 2013; Bryde et al., 2013; Ciribini et al., 2016), which is one of the most important aspects when planning and developing a construction project (Zou et al., 2017). BIM can specifically help in handling the high complexity which is inherent in modern constructions at the development and operation phases and hinders control of quality, time and cost in a project (Bryde et al., 2013). BIM also facilitates communication among the project's participants, which is a prerequisite for having a successful risk management (PMI, 2013). Finally, it contributes to project's coordination, through a great number of available collaboration tools for the project's stakeholders (Jupp, 2017).

To investigate the current level of use of BIM tools into risk management and identify the benefits and improvements that they offer, a literature review was carried out. Zou et al., (2017) have presented thoroughly the state-of-the-art concerning the use of BIM for risk management. Their conclusion was that while BIM-based risk management is a growing research interest for the AECOO industry, the last still, largely, depends on manual, empirical and cognitive processes for managing risks. Furthermore, they identified that BIM-based risk management tools are still in their infancy, while they are not covering the whole spectrum of risks but rather focus on specific types of them (e.g. safety risks) (Zou et al., 2017).

Following the Risk Breakdown Structure proposed by El-Sayegh (2008), Table 1 associates different types of risks sources with previous research efforts on the use of BIM for risk management in construction projects. As shown in Table 1, BIM technology has so far been addressed to tackle with internal risks, i.e. risks associated to the main stakeholders in developing a project, namely the designers, contractors, and suppliers. Some examples of such applications are: a) the use of BIM by Zhang et al. (2013) to reduce risks of 
injuries through automated hazards identification on the site, and b) the use of BIM in conjunction with Geographic Information Systems (GIS) by Irizarry, Karan and Jalaei (2013) to reduce late deliveries of materials on the site.

Table 1: An overview on how BIM is addressed for managing risks in construction projects

\begin{tabular}{|c|c|c|}
\hline \multicolumn{2}{|r|}{ Source } & Citation \\
\hline \multirow{4}{*}{ 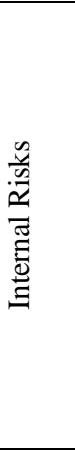 } & Owners & - \\
\hline & Designers & $\begin{array}{l}\text { Peckienė \& Ustinovičius, } \\
\text { 2017; Kelly \& Ilozor, 2016; } \\
\text { Al Hattab \& Hamzeh, } 2015\end{array}$ \\
\hline & Contractors & $\begin{array}{l}\text { Peckienè \& Ustinovičius, } \\
\text { 2017; Bråthen \& Moum, } \\
\text { 2016; Kim, Cho \& Zhang, } \\
\text { 2016; Barazzetti et al., 2015; } \\
\text { Whong \& Zhou, 2015; Chen } \\
\text { \& Luo, 2014; Bryde et al., } \\
\text { 2013; Zhang et al., 2013; }\end{array}$ \\
\hline & Suppliers & Irizarry et al., 2013 \\
\hline 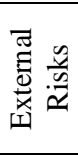 & $\begin{array}{c}\text { Political, Social } \\
\text { \& Cultural, } \\
\text { Economic, } \\
\text { Natural, Others }\end{array}$ & - \\
\hline
\end{tabular}

Therefore, the conclusion from the conducted literature review is that two main issues are interesting for further investigation: a) the use of BIM for managing external risks of construction projects is very limited if any, and b) the use of BIM for risk management is rather casebased as there is no description of a clear methodology in order to apply BIM for risk management (Zou et al., 2017). Both identified limitations prevent BIM from fully supporting and becoming a standard approach for risk management for construction projects. The goal of this paper is to propose such a methodology and demonstrate its application through an example of a building project.

\section{Methodology and analysis}

The project's lifecycle can be generally distinguished in four phases, namely initiation, planning, implementation and closing (Volkov \& Kuzina, 2016). The project's pre-selection phase is when conducting the respective feasibility studies, whose assumptions and baselines become the critical data that define along with existing regulations the project's requirements at the design phase. Furthermore, the design's requirements define for the project's developers the objectives to achieve during the implementation phase. BIM technology may be applied even from the feasibility studies' phase, but it definitely applies at the very early stages of the design phase. The initial drafts are usually designed in 2D plans, which then elaborate to $3 \mathrm{D}$ plans and BIM models that follow in the next versions. The created BIM models contribute to several calculations related to quantities of materials, tasks' schedules, costs and budget, etc., while they facilitate site planning and management. At the implementation phase, BIM models are required for organizing and controlling the construction process by monitoring activities, controlling outflows and timeline, etc. At this phase, BIM models are very critical for the project's development as they can provide adaptations of the design to real time conditions, something which is crucial in the dynamic environment of a construction project. Required changes of a qualitative or/and quantitative nature can be early identified, investigated for their impact and adopted properly in the context of a monitoring, risks management or facility management processes towards ensuring the project's unhindered development.

Managing risks with the use of BIM, currently, requires a combination of software solutions that should include:

- a BIM software program for designing the project's 3D model,

- a software program for project management,

- a software program for risk analysis, and

- a software program for construction management.

There are several criteria of choosing such solutions, including cost, easy use, etc.; however, the fundamental criteria are interoperability and compatibility of the various file formats of different software programs. In order to decide about the proper software solutions to apply, proper information flow (i.e., inputs and outputs of different nature to the modules of a fully automated model) between them is required. Figure 1 depicts the types of software programs used to support this information flow in BIM-based risk management in construction projects.

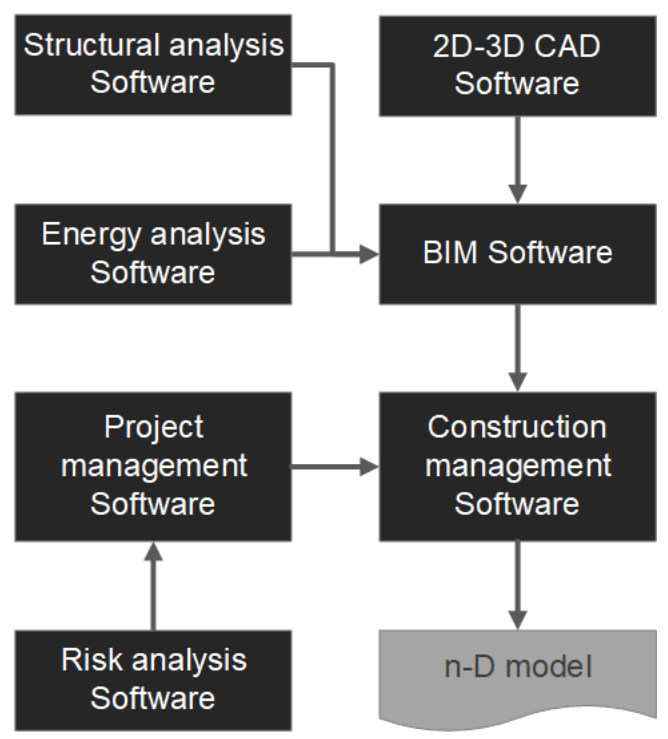

Figure 1: Information flow of software combination 
As shown in Figure 1 the final model produced is an $n$ dimensions model, where $n$ depends on the information that is included in the model. For instance, a 4D model includes information about geometry and time, a 5D model about geometry, time and cost, and so on. An example of a combination of software programs that was actually applied in the case study described in the Simulation section is the following:

- Revit 2017 by Autodesk for designing the 3D BIM model,

- MS Project by Microsoft for project management,

- Risky Project by Intaver for risk analysis, and

- NavisWorks 2017 by Autodesk for construction management.

The software products combined in this research are very well-known and used in practice, thus indicating that an integrated and largely computer-aided conducting of risk management is feasible for common practitioners that possess the appropriate respective theoretical background.

\section{Proposed methodology}

The proposed methodology consists of three stages, which are described in detail below.

\section{Stage 1}

The plans of the project are designed in 2D CAD software that must be compatible with a BIM software. For example, AutoCAD by Autodesk allows 2D and 3D designing, while its .dwg format can be imported into Autodesk's Revit, ensuring the required interoperability. The BIM software must produce an integrated unique model of the project with as many details as possible; therefore, several add-ins facilitating structural analysis, photorealistic rendering, energy analysis, etc. should be added to it. The output of the first stage is a BIM software's file (e.g., rvt in the case of Revit) with the project's full model. Figure 2 depicts the information flow at Stage 1.

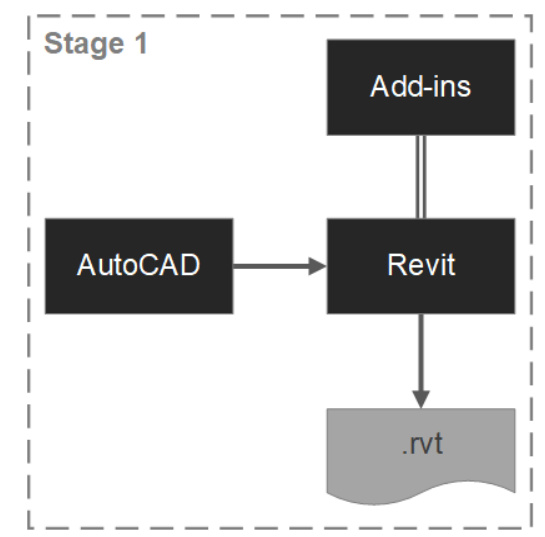

Figure 2: Information flow of Stage 1

\section{Stage 2}

Once the building's model is at hand the project's details must be inserted to allow project management. All necessary project tasks and their attributes (i.e. prioritization, start and finish times, resources, etc.) must be inserted through another software suite that allows scheduling, resources assignments, budget calculations and controls, etc. MS Project is an example of such software that was also used in this research.

As project management software does not allow full risk management (and whenever it does, this software is not compatible with BIM software), another software suite is required for managing project risks. This suite must be compatible with and operate either as a standalone program or as add-in to the project management software suite used. An example of such software solutions is RiskyProject that allows an integrated schedule and cost risk analysis of a project, along with a sensitivity analysis on risks, cost, duration, tasks' finish times, etc. Co-ordination of these software solutions produces a full file of project and risk management as shown in Figure 3.

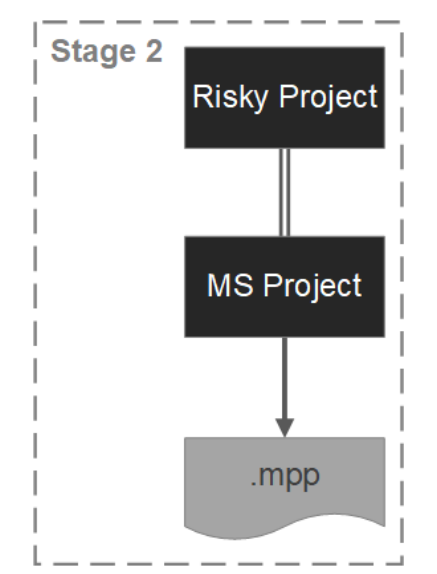

Figure 3: Information flow of Stage 2

Stages 1 and 2 are independent and can be run either simultaneously or asynchronously; however, it is helpful if Stage 1 precedes Stage 2, because changes in the building model affect the input at Stage 2.

Stage 3

The final stage integrates the outputs of previous stages with the use of a third appropriate software tool that enables such integration. In this case, NavisWorks by Autodesk, is selected as it is compatible with both. rvt and .mpp formats.

At this stage every scheduled task is assigned to the respective objects of the BIM model thus allowing simulation of different scenarios of the construction process showcased in respective videos. Figure 4 depicts the information flow at Stage 3. 


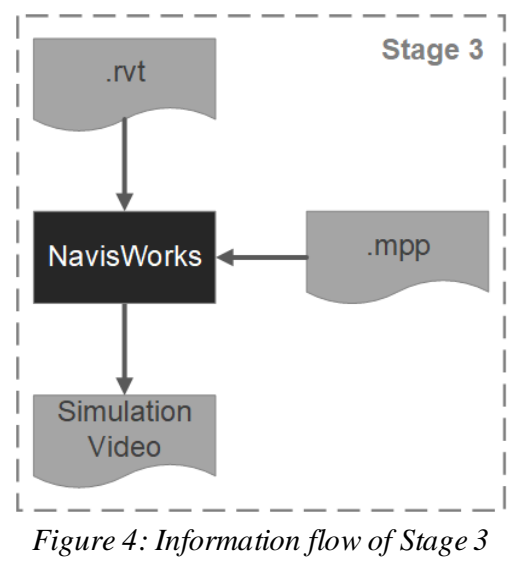

The total proposed methodology is depicted in Figure 5.

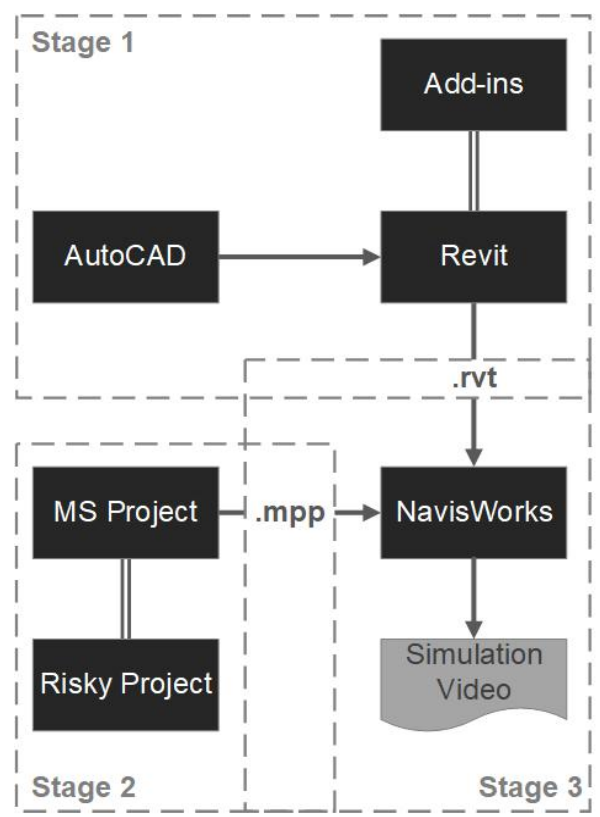

Figure 5: Information flow of proposed methodology

When the study team wants to examine and compare more than one scenario, the implementation of Stage 2 must be repeated as many times as the different scenarios. Figure 6 shows the implementation of Stage 2 for $n$ different scenarios.

\section{Simulation}

The proposed methodology is demonstrated through an example that represents the construction of a ground floor residence of $120 \mathrm{~m}^{2}$.

Firstly, the top view is designed in AutoCAD and the dwg file is imported to Revit to create the 3D model. Figure 7 showcases the BIM model with screenshots

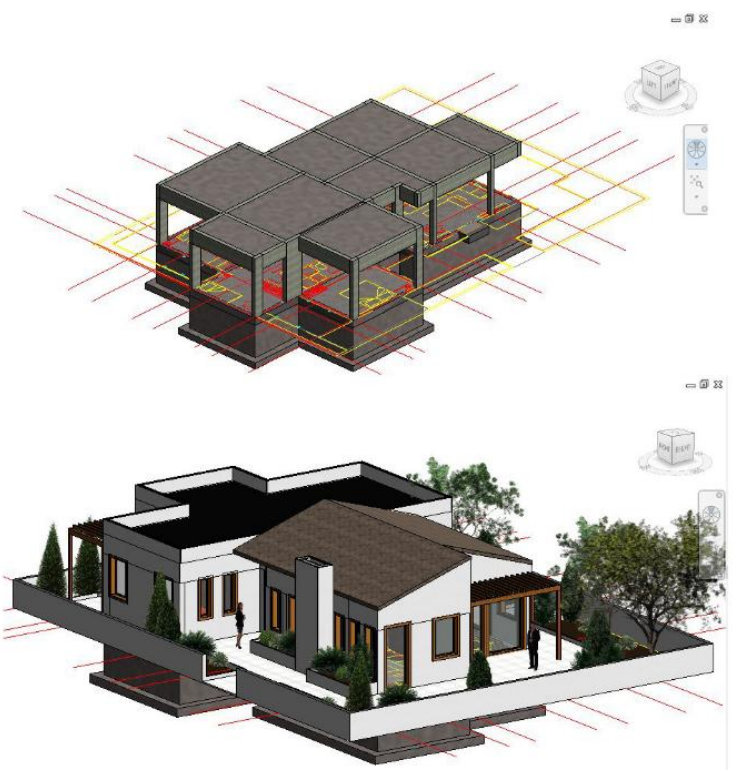

Figure 7: Screenshots of creating BIM model

A new parameter, the 4D_Task_ID, is added to the model's objects' properties as shown in Figure 8. This extra parameter facilitates the connection between the model's objects and the project's tasks, which is introduced at the methodology's Stage 3 and is essential for addressing to the BIM model the risks related to the several tasks. Filling the parameter's field with the ID number of the proper task links the BIM model with the project's schedule and concludes the implementation of the methodology's Stage 1.

$$
\text { Stage } 2.1
$$

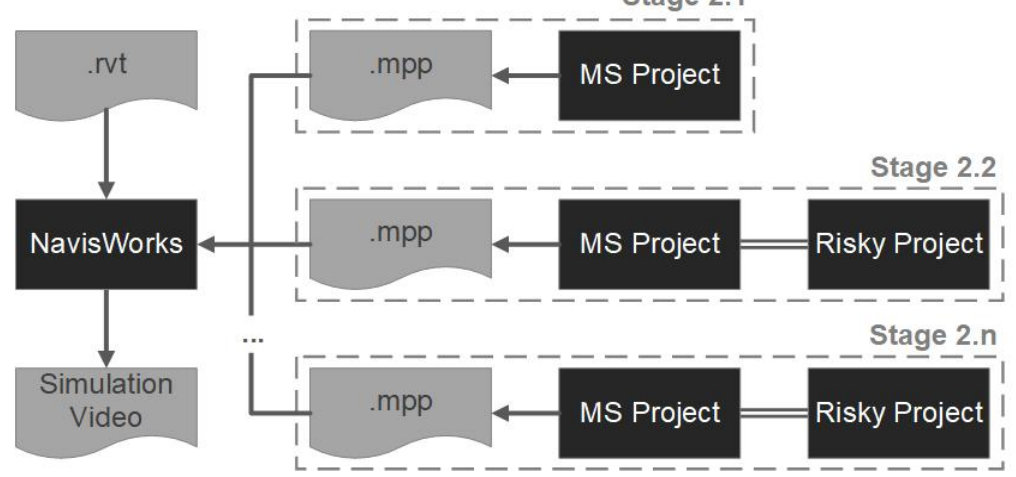

Figure 6: Information flow of Stages 2 \& 3 for examining more than one different scenarios 
Stage 2 includes the definitions of all tasks and their modelling in MS Project. Activities' sequence, duration and cost are set for every task. Then the program calculates the total project's duration and cost. The results are the following:

- Total duration: 135 days

- Total cost: $115,870.00 €$

Stage 2 proceeds with risk identification. In the presented case study, the most common - according to the literature presented in Table 1 - risks met during the construction phase of building projects are identified. These risks are listed in Table 2.

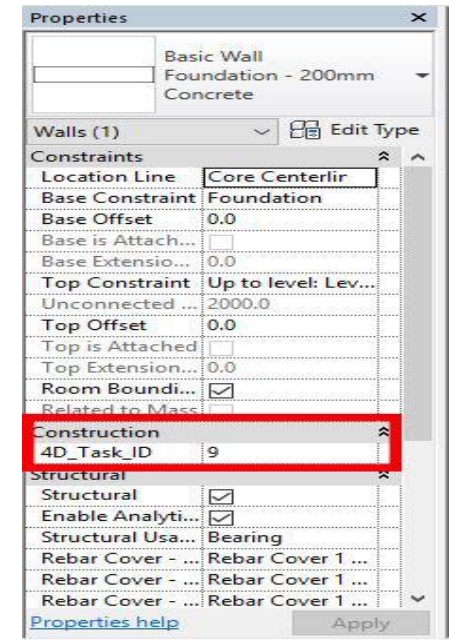

Figure 8: Adding the new parameter “4D_Task_ID” on Revit

Table 2: Identified risks of the current project

\begin{tabular}{|c|c|c|}
\hline & Source & Risk \\
\hline \multirow{6}{*}{$\begin{array}{l}\bar{\Xi} \\
\stackrel{\Xi}{0} \\
\stackrel{\Xi}{\Xi}\end{array}$} & Owners & $\begin{array}{l}\text { Change of design - Improper } \\
\text { intervention }\end{array}$ \\
\hline & Designers & $\begin{array}{c}\text { Defective design - } \\
\text { Deficiencies in drawings }\end{array}$ \\
\hline & \multirow{3}{*}{ Contractors } & Construction accidents \\
\hline & & Poor quality \\
\hline & & Low productivity \\
\hline & Suppliers & Delay of material supply \\
\hline \multirow{2}{*}{ 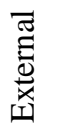 } & Natural & Unexpected weather \\
\hline & Economic & Rise material's value \\
\hline
\end{tabular}

The application of BIM technology can contribute to the mitigation of some of these risks (e.g. deficiencies in drawings can be minimized thanks to the integrated 3D BIM model).
The introduction of risks allows the creation of different scenarios based on the created BIM model; in the example's case, two scenarios are proposed, namely the optimistic and the pessimistic one. The optimistic scenario considers that the application of BIM technology can reduce to the maximum both the probability of the modeled risks and their impact on the project's duration and cost. On the other hand, the pessimistic scenario, considers that the application of BIM technology contributes only to a minimum reduction of them. To illustrate the studied example the arbitrary - yet plausible - values shown on Table 3 are used for an indicative subset of risks. The identified risks are then introduced into Risky Project and subsequently to MS Project where they are assigned to the several tasks. For each scenario a different file is created that addresses the different values of the risks' determinants (i.e. chance and outcome of the risk occurrence), and the simulations' results (i.e., duration and cost for different values of risks) are presented in Figure 9. The new durations and costs for each scenario are the following: a) for the optimistic scenario the total duration is 142 days and the total cost is 121,112.00€, b); for the pessimistic scenario the results are 163 days and 125,420.00€, respectively. Figures 9 and 10 depict the simulation results in Risky Project.

After the simulations three .mpp files are created each one corresponding to a different scenario, i.e. the norisk, the optimistic, and the pessimistic one. These files constitute the final outputs of Stage 2.

Continuing with the methodology's Stage 3, the.mpp and .rvt files are imported to NavisWorks, thus, achieving every task's assignment to the proper objects in the model. The simulation in NavisWorks produces the videos of the construction process for each scenario. Figures 11 to 19 depict screenshots of these videos.

\section{Conclusions}

Risk management is one of the most important processes in planning and constructing a project. BIM technology can undoubtedly facilitate this process, thanks to its advantages. The - as accurate as possible and in time risk assessment can reduce time and cost, while increase quality and safety of a construction project. The conventional methods of risk management require many hours of team work and a great amount of data. BIM software expedites the risk management process as the produced models include all the required information, in a uniform manner, thus facilitating the project's stakeholders' understanding and acceptance of the risk management process and outcome.

A three-stage methodology is proposed in this paper that introduces the combination of four software suites. At the first stage, the BIM model of the project is created, then, at the second one, the current risks are 
Table 3: Chances and outcomes for every risk

\begin{tabular}{|l|c|c|c|c|c|}
\hline \multirow{2}{*}{ Risk } & \multicolumn{2}{c}{ Pessimistic Scenario } & \multicolumn{2}{c|}{ Optimistic Scenario } \\
\hline \multirow{3}{*}{ Defective design } & Relative delay & Chance & Outcome & Chance & Outcome \\
\cline { 2 - 6 } & Relative cost increase & $20 \%$ & $20 \%$ & $5 \%$ & $5 \%$ \\
\hline \multirow{2}{*}{$\begin{array}{l}\text { Construction } \\
\text { accidents }\end{array}$} & Relative delay & $10 \%$ & $10 \%$ & $5 \%$ & $10 \%$ \\
\hline \multirow{2}{*}{\begin{tabular}{l} 
Poor quality \\
\cline { 2 - 6 }
\end{tabular}} & Relative cost increase & $10 \%$ & $20 \%$ & $5 \%$ & $20 \%$ \\
\hline \multirow{2}{*}{ Change of design } & Relative delay & $20 \%$ & $10 \%$ & $10 \%$ & $5 \%$ \\
\cline { 2 - 6 } & Relative cost increase & $20 \%$ & $15 \%$ & $10 \%$ & $15 \%$ \\
\hline
\end{tabular}
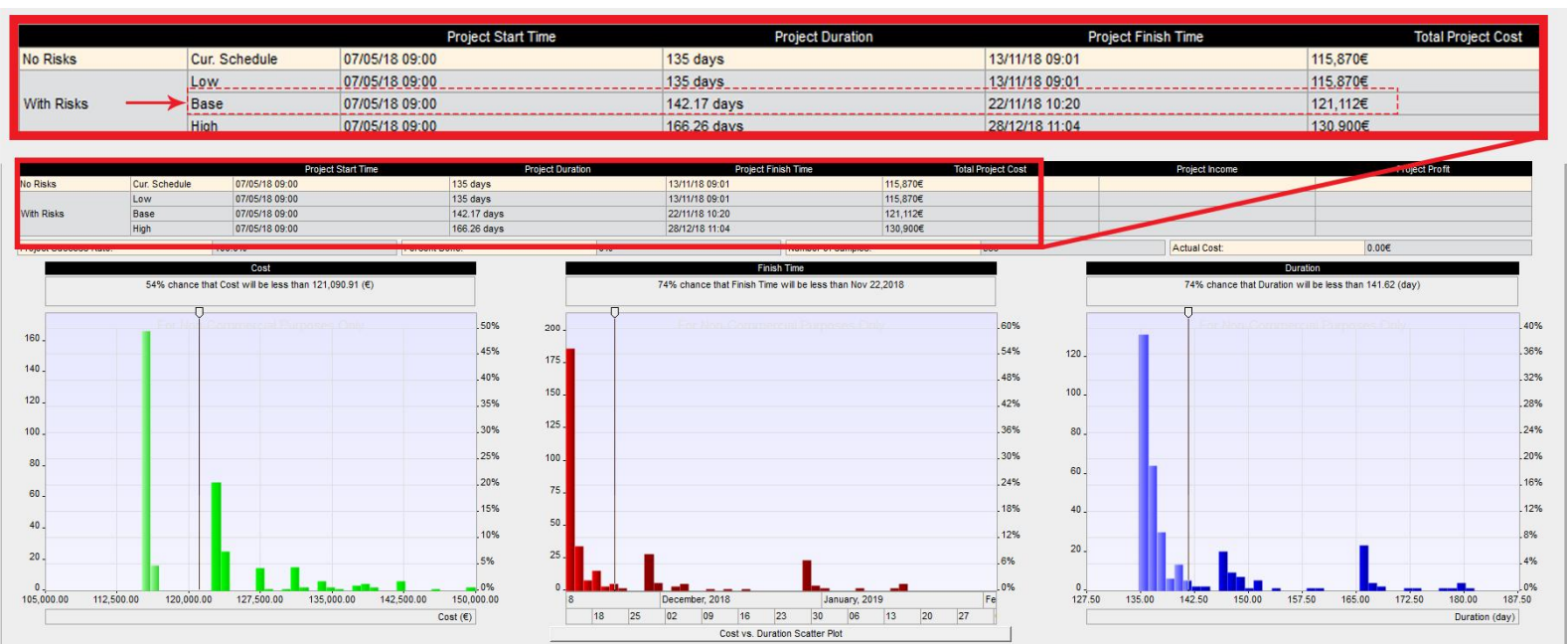

Figure 9: Risk assessment for the optimistic scenario

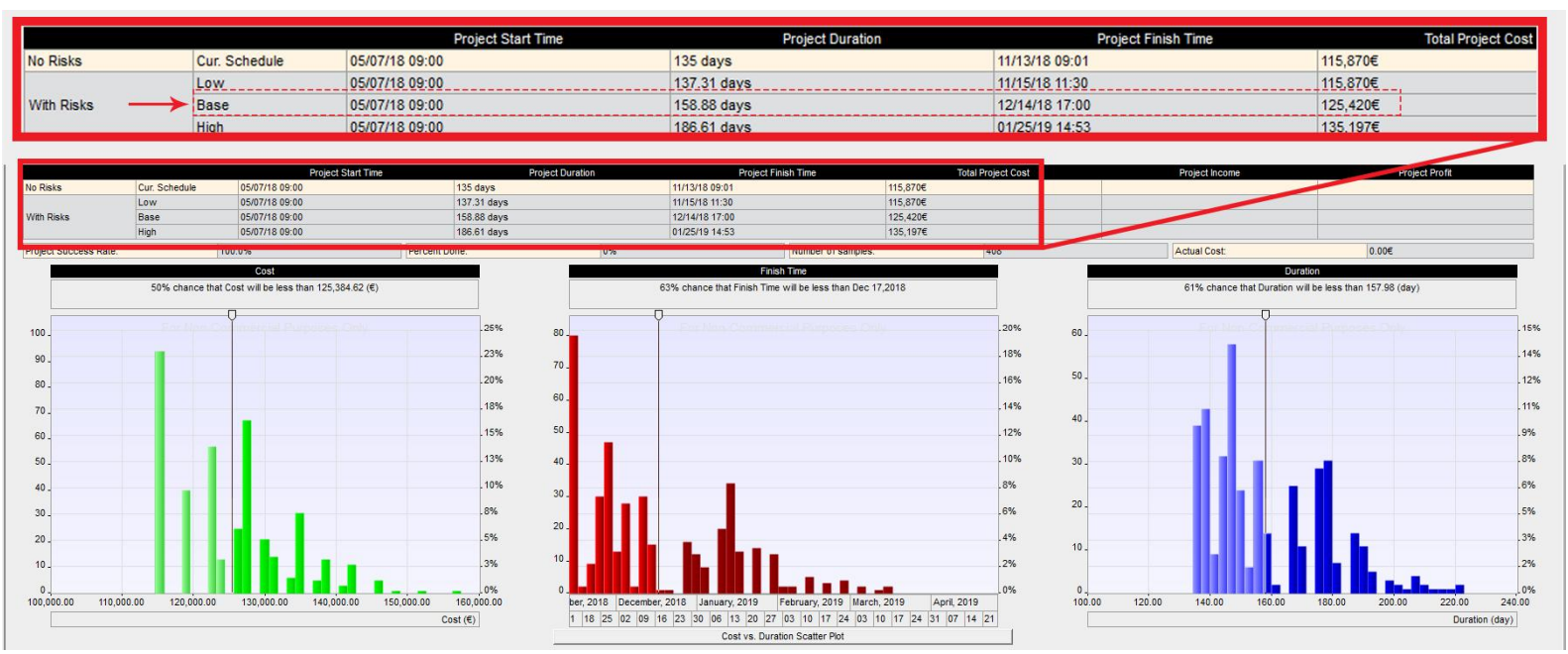

Figure 10: Risk assessment for the pessimistic scenario 
identified and analyzed, and, finally, at the third stage, all elements are integrated to a single model and risk assessment arise. The advantages of the proposed methodology are that:

- It is applicable for all types of projects throughout their whole life cycle and especially at the implementation and design phases.

- The results are presented in a clear and comprehensible way and they can be studied even by non-specialists.

- Many different risk scenarios can be examined using a unique model for the project.

- The proposed software combination allows time and error reductions, especially during data transfer.

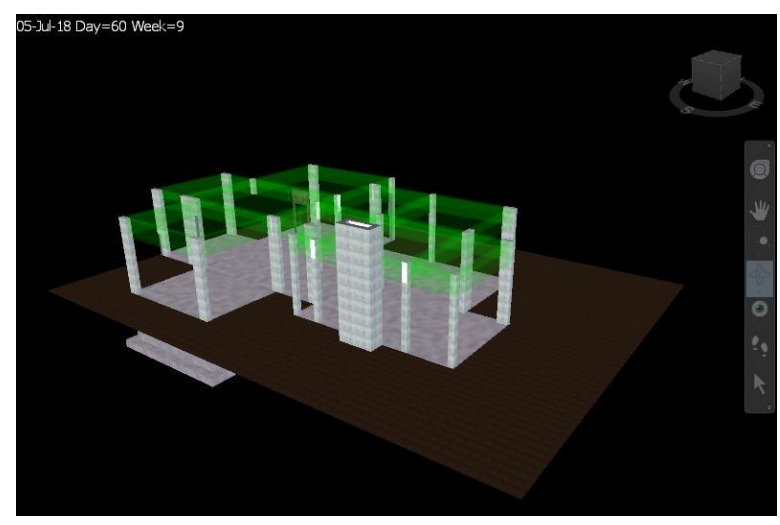

Figure 11: Simulation video's screenshots from $60^{\text {th }}$ day for the no-risk scenario

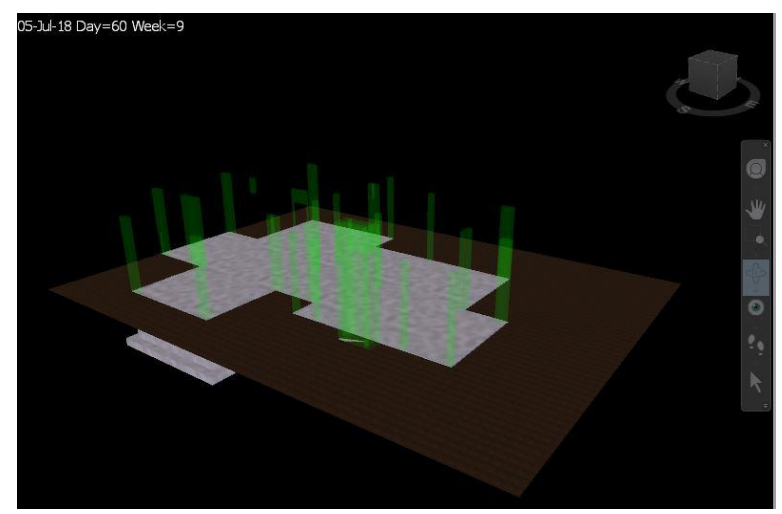

Figure 12: Simulation video's screenshots from $60^{\text {th }}$ day for the pessimistic scenario

On the other hand, there are several shortcomings that need to be confronted, including the following:

- Only internal risks of the project can be fully managed with the use of BIM software. External risks are generally non-technical and while some of them - can be modelled through BIM, they can be mitigated only by attempting to keep low the impact of their consequences upon occurrence, rather than taking precautionary methods to deal with their sources.

- Risk identification is not automated and specialist's experience is required.

- Risks that cannot be assigned to the model's objects require a different approach to get included in the analysis. In this way the risks management process becomes fragmented and complicates co-ordination.

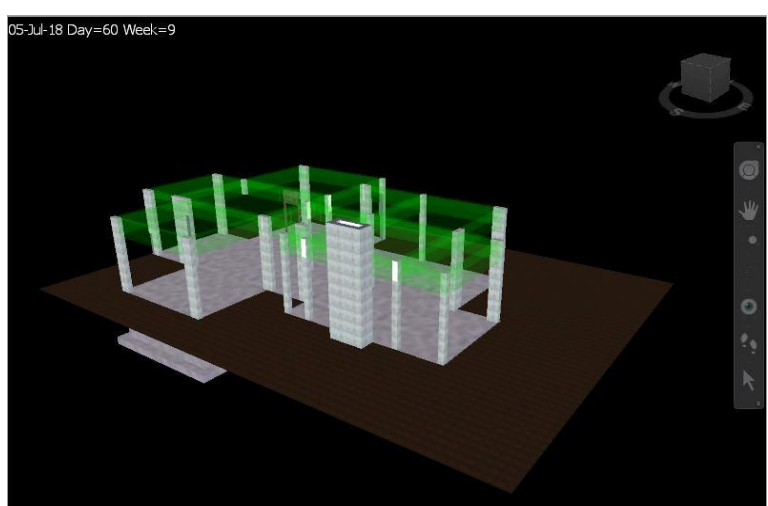

Figure 13: Simulation video's screenshots from $60^{\text {th }}$ day for the optimistic scenario

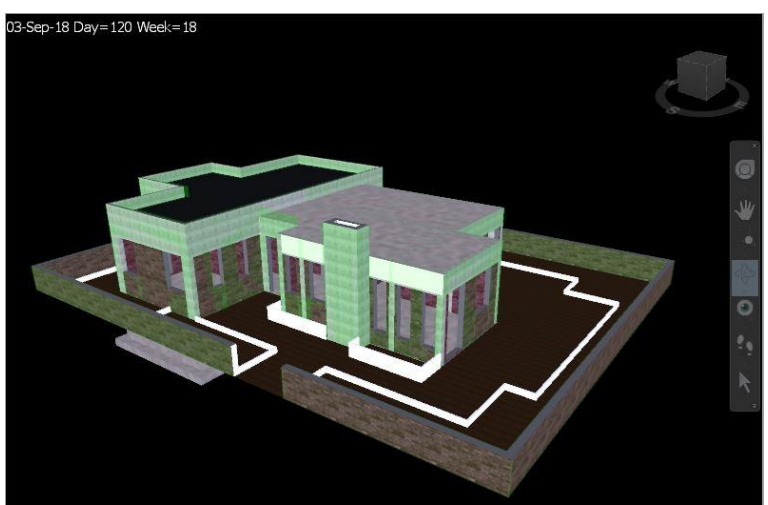

Figure 14: Simulation video's screen shots from 120th day for the no-risk scenario

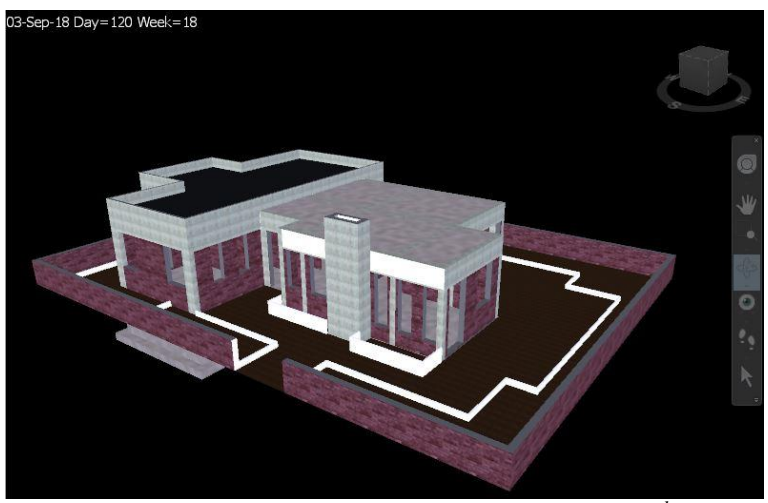

Figure 15: Simulation video's screenshots from $120^{\text {th }}$ day for the pessimistic scenario 
- The whole process of the methodology is not fully automated as several imports and exports of files are required.

- Different software programs' versions may obstruct information flow (e.g. Revit and NavisWorks should have common year's versions to collaborate) as, often, software updates result to incompatibilities between older and recent versions of the same product.

Future work could focus on the further development of the proposed methodology especially regarding: a) the inclusion of a more comprehensive list of risks that would address also more risks typologies (including external ones), b) the further limitation of manual processes most probably with the use of augmented reality, and c) the inclusion in the methodology of a well-defined decision-making process to select the appropriate software. Future work could, also, include the application of the methodology to construction projects of different types (e.g., infrastructure), level of complexity and demands.

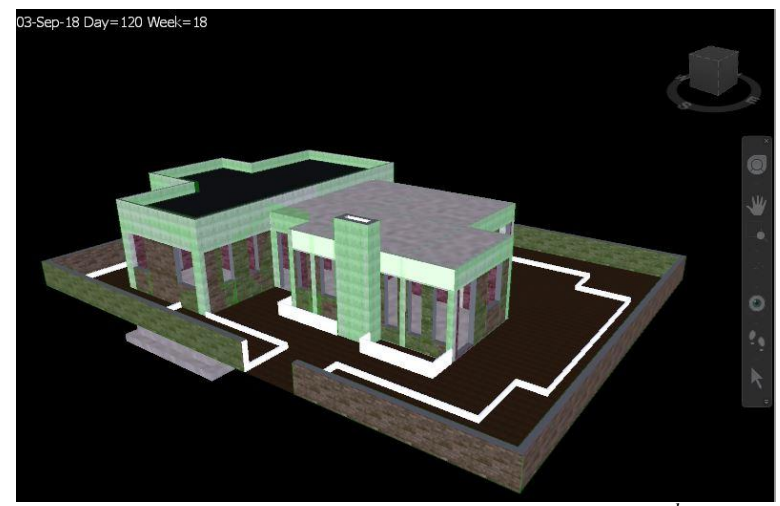

Figure 16: Simulation video's screenshots from $120^{\text {th }}$ day for the optimistic scenario

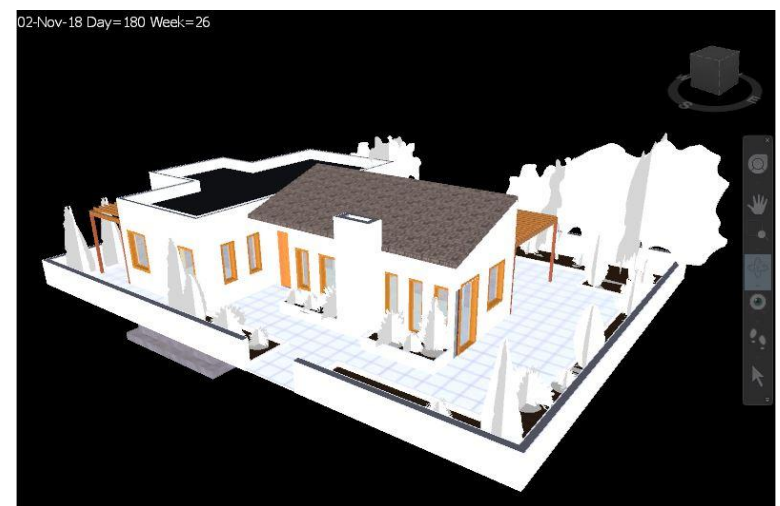

Figure 17: Simulation video's screenshots from $180^{\text {th }}$ day for the no-risk scenario

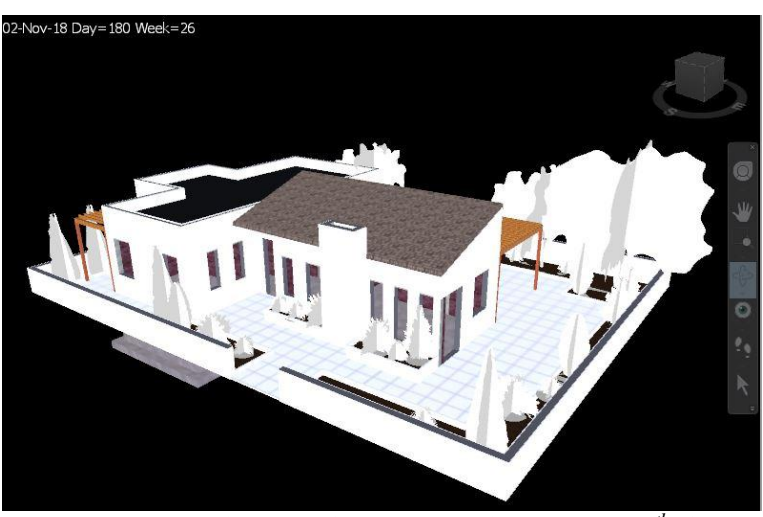

Figure 18: Simulation video's screenshots from $180^{\text {th }}$ day for the pessimistic scenario

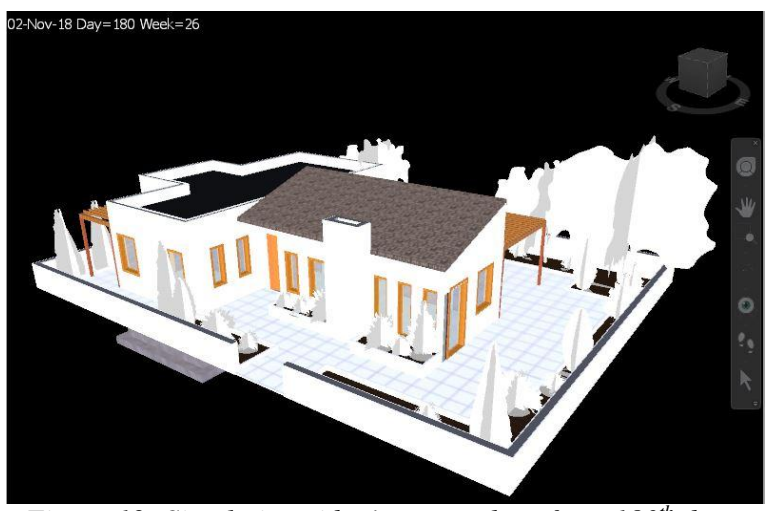

Figure 19: Simulation video's screenshots from $180^{\text {th }}$ day for the optimistic scenario

\section{References}

Al Hattab, M. \& Hamzeh, F. (2015) Using social network theory and simulation to compare traditional versus BIM-lean practice for design error management. Automation in Construction, 52, p.pp.59-69.

Barazzetti, L., Banfi, F., Brumana, R., Gusmeroli, G., Previtali, M. \& Schiantarelli, G. (2015) Cloud-toBIM-to-FEM: Structural simulation with accurate historic BIM from laser scans. Simulation Modelling Practice and Theory, 57, p.pp.71-87.

Bråthen, K. \& Moum, A. (2016) Bridging the gap: bridging BIM to construction workers. Engineering, Construction and Architectural Management, 23, p.pp.751-764.

Bryde, D., Broquetas, M. \& Volm J.M. (2013) The project benefits of Building Information Modelling (BIM). International Journal of Project Management, 31, p.pp.971-980.

Chen, L. \& Luo, H. (2014) A BIM-based construction quality management model and its 
applications. Automation in Construction, 46, p.pp.64-73.

Ciribini, A.L.C., Mastrolembo Ventura, S. \& Paneroni, M., (2016) Implementation of an interoperable process to optimise design and construction phases of a residential building: A BIM Pilot Project. Automation in Construction, 71, p.pp.62-73.

Eadie, R., Browne, M., Odeyinka, H., McKeown, C. \& McNiff, S. (2013) BIM implementation throughout the UK construction project lifecycle: An analysis. Automation in Construction, 36, pp.145-151.

Eastman, C., Teicholz, P., Sacks, R. \& Liston, K. (2008) BIM Handbook: A Guide to Building Information Modelling for Owners, Managers, Designers, Engineers and Contractors. John Wiley and Sons, New Jersey, Hoboken, p.pp.1-30.

El-Sayegh, S.M. (2008) Risk assessment and allocation in the UAE construction industry. International Journal of Project Management, 26, p.pp.431-438.

EU BIM Taskgroup (2017) Handbook for the introduction of Building Information Modelling by the European Public Sector.

Farnsworth, C.B., Beveridge, S., Miller, K.R. \& Christofferson J.P. (2015) Application, Advantages and Methods Associated with Using BIM in Commercial Construction. International Journal of Construction Education and Research, 11:3, p.pp.218-236.

Irizarry, J., Karan, E.P. \& Jalaei F. (2013) Integrating BIM and GIS to improve the visual monitoring of construction supply chain management. Automation in Construction, 31, p.pp.241-254.

Jupp, J. (2017) 4D BIM for Environmental Planning and Management. Procedia Engineering, 180, p.pp.190-201.

Kelly, D. \& Ilozor, B. (2016) A Quantitative Study of the Relationship between Project Performance and BIM Use on Commercial Construction Projects in USA. International Journal of Construction Education and Research, DOI: 10.1080/15578771.2016.1202355.

Kim, K., Cho,Y. \& Zhang, S. (2016) Integrating work sequences and temporary structures into safety planning: Automated scaffolding-related safety hazard identification and prevention in BIM. Automation in Construction, 70, p.pp128142.

Lam, T.T., Mahdjoudi, L. \& Mason, J. (2017) A framework to assist in the analysis of risks and rewards of adopting BIM for SMEs in the UK. Journal of Civil Engineering and Management, DOI: 10.3846/13923730.2017.1281840.

Peckienè, A. \& Ustinovičius, L. (2017) Possibilities for Building Spatial Planning Using BIM Methodology. Procedia Engineering, 172, p.pp.851-858.

Project Management Institute (2013) A guide to the Project Management Body of Knowledge. Project Management Institute, $5^{\text {th }}$ edition.

Volkov, A. \& Kuzina, O. (2016) Complementary assets in the methodology of implementation unified information model of the city environment project life cycle. Procedia Engineering, 153, p.pp.838-843.

Wong, J.K.W. \& Zhou, J. (2015) Enhancing environmental sustainability over building life cycles through green BIM: A review. Automation in Construction, 57, p.pp.156-165.

Zhang, S., Teizer, J., Lee, J.K., Eastman, C.M. \& Venugopal, M. (2013) Building Information Modeling (BIM) and Safety: Automatic Safety Checking of Construction Models and Schedules. Automation in Construction, 29, p.pp.183-195.

Zou, Y., Kiviniemi, A. \& Jones, S.W. (2017) A review of risk management through BIM and BIM-related technologies. Safety Science, 97, p.pp.88-98. 